\author{
تأثير طرائق الري ومغنطة المياه في الصفات النوعية لزهزة الثمس وكفاءة استعمال الماء \\ محمد مبارك علي عبد الرزلق \\ أستاذ مساعد \\ قسم المحاصيل الحقلية - كلية الزراعة - جامعة بغداد

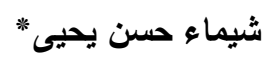 \\ وزارة الزراعة - دائرة الغابات والتصحر
}

Shama.yahya@yahoo.com

المستخلص

نفذت تجربة حقلية خلال الموسمين الربيعيين 2012 و2013 في حقل تجارب قسم المحاصيل الحقلية - كلية الزراعة - جامعة بغداد، بهذف معرفة استجابة الصفات النوعية لمحصول زهرة الثمس صنف أقمار لطرائق الري وتقانة مغنطة مياه الري وكفاءة استعمال الماء. نفذت التجرية بترتيب الألواح

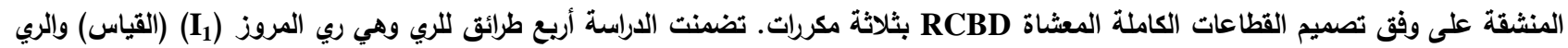

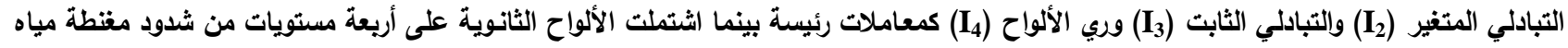

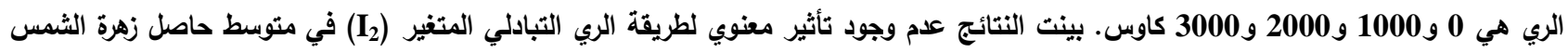

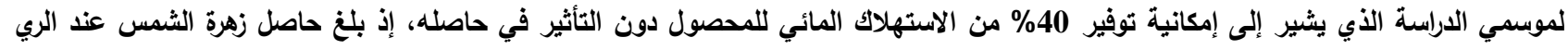

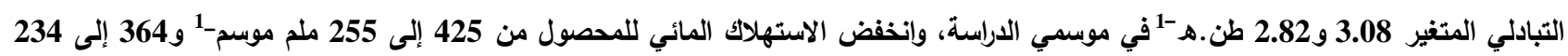

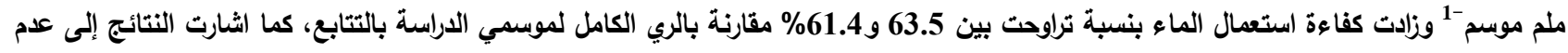

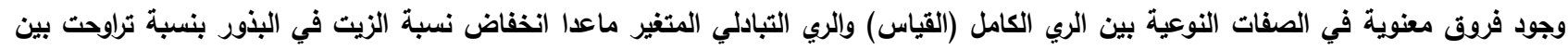

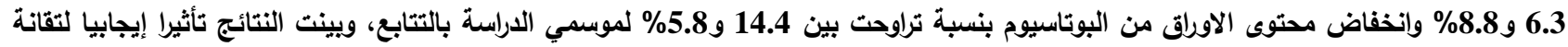

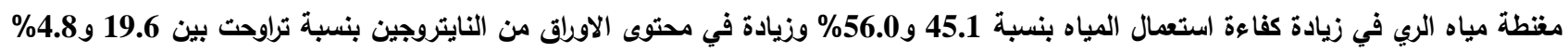

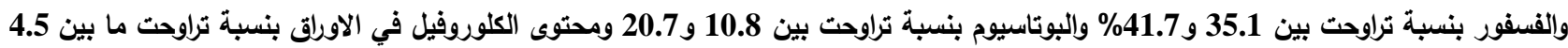
و7.6\% ونسبة الزيت في البذور بين 5.0 و5.6\%. كان التداخل معنويا بين عاملي الدراسة في بعض الصفات بنات المدروسة.

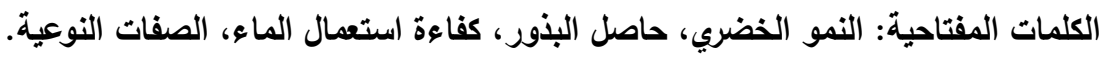
" البحث مستل من رسالة ماجستير للباحث الأول.

The Iraqi Journal of Agricultural Sciences -920-929: (4) 48/ 2017

Yahya \& Abdul-Razaq

\title{
EFFECT OF IRRIGATION METHODS AND MAGNETIZATION OF WATER ON QUALITY OF SUNFLOWER AND WATER USE EFFICIENCY \\ ${ }^{1}$ Sh. H. Yahya* \\ Researcher \\ ${ }^{2}$ M. M. A. Abdul-Razaq \\ Assist. Prof.
}

${ }^{1}$ Ministry of Agric. - State of Forstes and Desertification

${ }^{2}$ Dept. of Field Crops - Coll. of Agric. - Univ. of Baghdad

\section{ABSTRACT}

Shama.yahya@yahoo.com

This experiment was carried out at the experimental farm of Field Crop Department, College of Agriculture, university of Baghdad, during two spring seasons of 2012 and 2013 to study the response of quality characteristics of sunflower cultivar Akmar to the irrigation methods and water of magnetization technology and water use efficiency. The experiment was laid out as a split plot in randomized complete block design (RCBD) with three replications. Four irrigation methods were used as main plots, [Farrow irrigation $\left(\mathrm{I}_{1}\right)$, unfixed alternate furrow irrigation $\left(\mathbf{I}_{2}\right)$, fixed alternate furrow irrigation $\left(\mathbf{I}_{3}\right)$ and basin irrigation $\left(\mathbf{I}_{4}\right)$, while four levels of magnetized water $(0,1000,2000$ and 3000) Gauss were used as sub plot treatments. The results revealed that unfixed alternate furrow irrigation method could reduce irrigation water by $40 \%$, and it was irrigation water reduced from 425 to $255 \mathrm{~mm}$ per season in 2012th season and reduced from 364 to $234 \mathrm{~mm}$ per season in 2013 season were an increment of water use efficiency (WUE) by $63.5 \%$ and $61.4 \%$ were accrued during growing seasons respectively in comparison with full irrigation treatment $\left(I_{1}\right)$. The Leaves potassium content decreased by14.4 to $5.8 \%$ for both seasons respectively. No significant effect was detected between $I_{1}$ and $I_{2}$ in qualitative traits except reduction in oil percentage as it reaches 6.3 to $8.8 \%$ in both seasons respectively. Results displayed a positive effect of using magnetized irrigation water on all measured traits. WUE increased by 45.1 to $56 \%$, nitrogen leaf content by 19.6 and $4.8 \%$, phosphor leaves content by 35.1 and $41.7 \%$, potassium leaves content by 20.7 and $10.8 \%$, chlorophyll content by 4.5 to $7.6 \%$, seed oil content by 5.0 to $5.6 \%$. Interaction relations between experiment treatments were significant in some of studded traits.

Key words: vegetative growth, seed yield, WUE, quality characteristics.

*Part of M.Sc. thesis of the first auther. 
المتبادل سواء الثابت أو المتغير من الطرائق التي استعملت للوصول إلى تخفيض مقدار الهدر في مياه الري سواء بالتبخر أو فقدانها بالتسرب إلى خارج منطقة الجذر وبالنتيجة

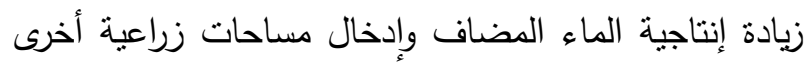
بكميات المياه المضافة نفسها. برز في الآنة الاخيرة استعمال نقانات المغنطة في مجالات الحياة المتعددة وقد لكاه

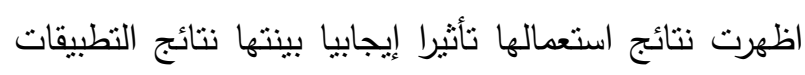
التي اجريت عليها، إذ سجل تأثيرها في تكييف وتحسين خواص مياه الري وإعادة نرتيب جزيئات الماء ذات التوزيع العشوائي وجعلها اكثر انتظاما (14). كما أن استعمال ثقانة مغنطة مياه الري ادت إلى كثير من التحسينات في خواص الماء كتعديل الكثافة والثند السطحي واللزوجة ورفع قابلية النية

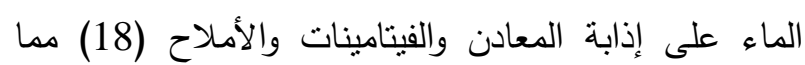

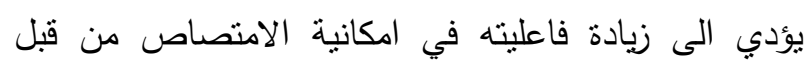

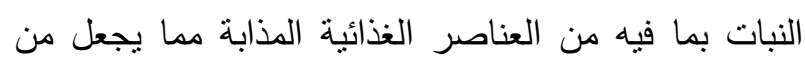

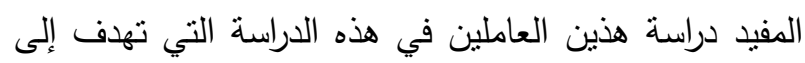
تحديد أفضل طريقة لري محصول زهرة الثمس باستعمال

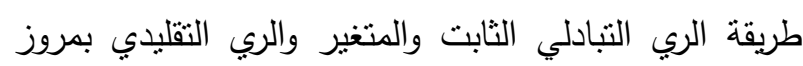
وبألواح فضلا عن معرفة نأثير طرائق الري واستعمال تقانة

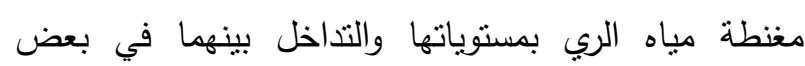
الصفات النوعية لزهرة الثمس.

المواد والطرائق

نفذت تجربتان حقليتان خلال الموسمين الربيعيين 2012 و2013 في حقل التجارب التابع لقسم المحاصيل الحقلية-

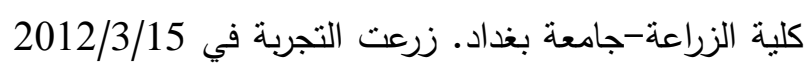
و2013/3/13 وحصدت في 2012/6/15 و 2013/6/20 للموسمين بالتتابع. سمدت أرض التجربة في كلا الموسمين بالسماد المركب NPK (18-18-0) بمعدل 540 كغم هـ -19 دفعة واحدة قبل الزراعة، ثم اضيف سماد اليوريا بمعدل 160

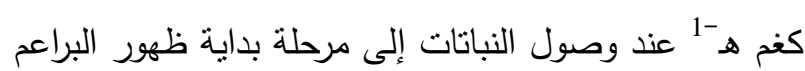
الزهرية (3). زرعت بذور زهرة الثمس صنف أقمار المفتوح التلقيح في وحدات تجريبية مساحتها 16.28 م وبكثافة نباتية

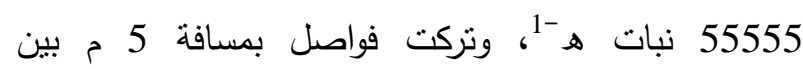
المكررات و 1 م بين المعاملات لدنع حركة الماء بين الوحدات التجريبية. تضمنت الوحدة التجربية ستة مروز زرعت على جانب واحد، وبعد اكتمال البزوغ اجريت عملية
المقدمة

يعد محصول زهرة الثمس .Helianthus annuus L من المحاصيل الهامة في العالم التي تزرع من أجل زيتها والذي يعد من الزيوت الصالحة للتغذية البشرية (21) نتيجة لارتفاع لتراع لترن سيولته إلى جانب انخفاض نسبة الأحماض الدهنية المشبعة لتربه التي تؤدي دورا هاما في أمراض القلب وتصلب الثرايين،

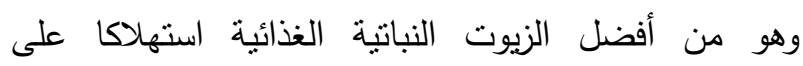
المستوى العالمي (8) فضلا عن استعمال الزيت في صناعة

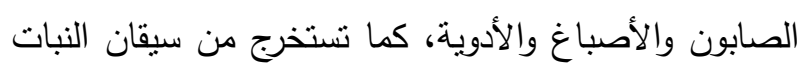

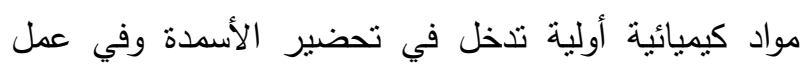
الزجاج (1). يصنف زهرة الثمس ضمن المحاصيل المنخفضة إلى المنوسطة الحساسية للجفاف (12)، ويتحمل لزهلف

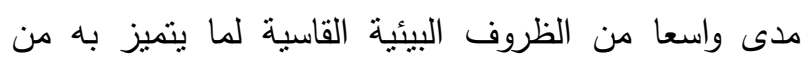

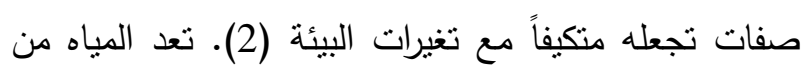

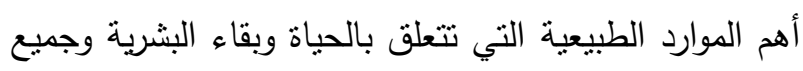
انشطتها في مختلف المجالات ولاسيما في مجال الزراعة بالئاء

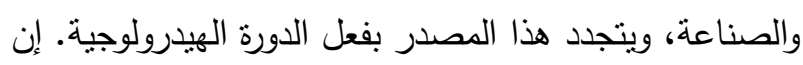
انخفاض حجم المباه السطحية قياسا بمساحة الأراضي القابلة للزراعة وقلة معدلات الأمطار الساقطة نتيجة وقوع العراق

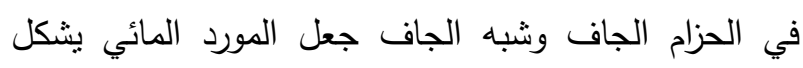
محددا إنتاجيا أوليا أمام التوسع في الزراعة الإنهاف الاروائية، فضلا عما يصاحب هذه الندرة من تقلبات مناخية شديدة ودورات الجفاف من تزايد المد الصحراوي وما ينجم عن ذلك من من من ضياع لمساحات كبيرة فضلا عن تأثنير الجفاف في الانظمة لنداف والخزانات المائية والجوفية (17). إن مسألة تأمين الماء اصبحت ضرورة حياتية واقتصادية ذات علاقة مباشرة بمستقبل البلدان، ويعد تحقيق الأمن المائي الهدف الرئيس

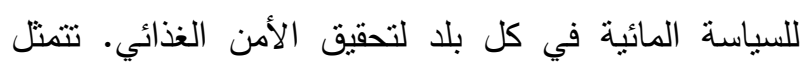
مشكلة المياه اليوم ومستقبلا بتتامي الطلب على لمي الموارد

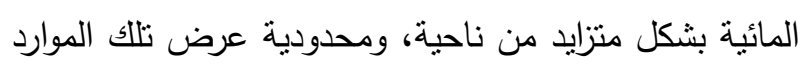

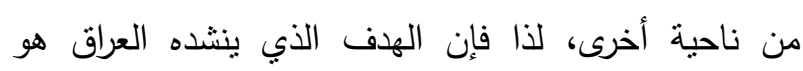

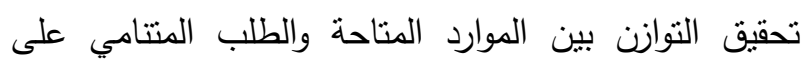

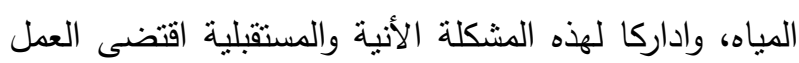
على توفير إدارة جيدة لمياه الري باستعمال تقانات وطرائق

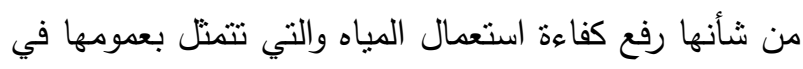
استعمال الري الناقص بأثكاله المختلفة. تعد طريقة الري الرياه 
وزنت وقدر المحتوى الرطوبي فيها بحسب المعادلة الواردة في

:(11) Hillel

$$
\mathrm{p} w=\left(\frac{M s w-M s}{M s}\right) 100
$$

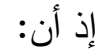

Pw

Msw

Ms

طريقة الري

نم الري بأنابيب بلاستيكية مرنة مربوطة بمضخة مثبتة على لى ملى

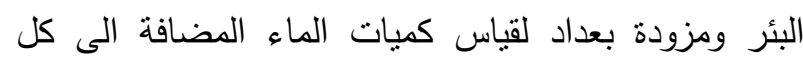
وحدة تجريبية. اضيفت كميات منساوية من ماء الري عند الزراعة الى السعة الحقلية لضمان البزوغ، ثم رويت النباتات عند استتزاف 50\% من الماء الجاهز وبحسب المعادلة كohnke

$$
\text { كما مبين في جدول } 1 .
$$

$W=a \cdot A s\left(\frac{\% P w^{F c}-\% P w^{w}}{100}\right) \times \frac{D}{100}$

إذ أن: W = حجم الماء الواجب إضافته خلال رية (م). = a As = PW ${ }^{\mathrm{Fc}}$ عند السعة الحقلية (بعد الري). = Pw

$$
\text { = D }
$$

وتم حساب الرطوبة الحجمية التي يكون عندها الري بحسب لتب

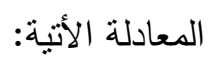

\section{$Q v=Q w \times \partial b$}

إذ أن: Qv= المحتوى الرطوبي على أساس الحجم. = المحتوى الرطوبي على أساس الوزن. المفافة = Db

الصفات المدروسة

1. محتوى الأوراق من NPK: اخذت عينة من الاوراق العلوية كاملة الاتساع (الورقة رقم 4-5) في مرحلة التزهير لكل معاملة ووضعت في أكياس ثم غسلت بالماء للتخلص الته

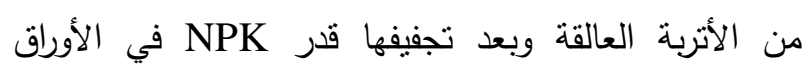

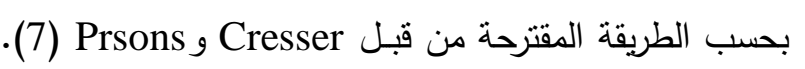

الخف إلى نبات واحد بالجورة. نالت المعاملات 12 رية خلال موسم النمو وتمت مكافحة الادغال بالتعشيب بدوياً كلما دعت الحاجة لذلك. استعمل ترنيب الألواح المنشقة بتصميم القطاعات الكاملة المعشاة (RCBD) بثلاثة مكررات، فقد مثلت الالواح الرئيسة معاملات طرائق الري وهي الري لسواقي

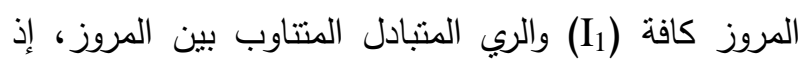
يروى بين ساقية وأخرى بشكل متتاوب (I2) والري المتبادل

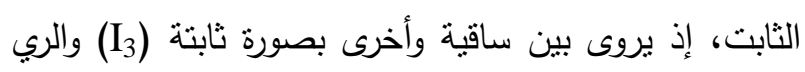

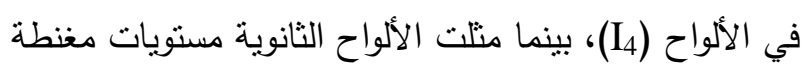

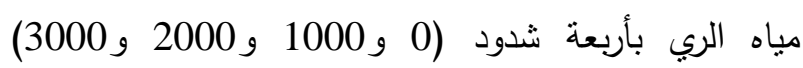
كاوس. تم تحضير الأرض للزراعة على وفق التصديم المستعمل في التجربة للموسمين. تضمنت معاملات طرائق تأق الري للمروز ري سواقي المروز كافة أما معاملة الري دئي المتتاوب فكان ري المروز الزوجية العدد (6 و 4 و 2) بين رية وأخرى إذ تروى المروز الفردية العدد (1 و 3 و 5) وهكذا وتنتمر طول مدة نمو المحصول، أما معاملة الري المتتاوب الثابت ففيها تروي المروز الفردية العدد فقط (1 و 3 و 5)

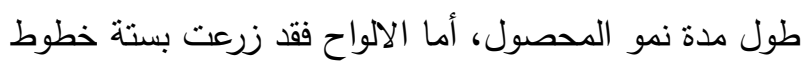

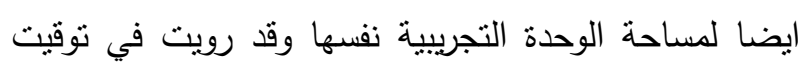

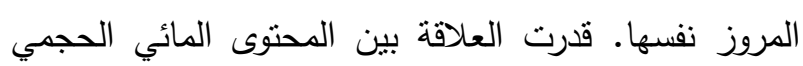

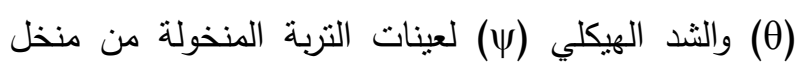
قطر فتحاته 2 ملم والمحتوى الرطوبي عند الثدود 33 و 100 الثين و500 و1000 و و1500 كيلو باسكال لتقدير سعة احتفاظ

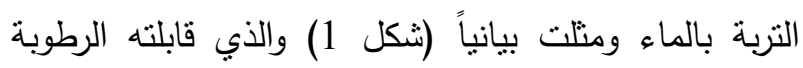
الحجمية النقطة التي بدأت من 0.31 إلى 0.15 للسعة الحقلية ونقطة الذبول بالتتابع، ومنها تم تحديد الماء الجاهز في التربة من الفرق بينهما. قياس المحتوى الرطوبي للترية استعملت الطريقة الوزنية لقياس رطوبة التوبتهية التربة ومتابعة التغيرات الرطوبية في التربة وتحديد وقت الارواء بأخذ نماذج التحنة

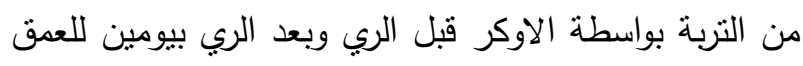

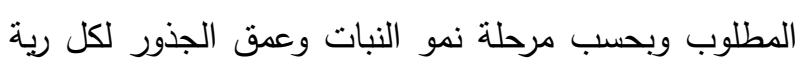
ووضعت في علب الالمنيوم ووزنت وهي رطبة، ثم وضعت ندو في فرن (Microwave Oven) ولمدة اثثتي عشرة دقيقة بعد أن نم تعيير مدة التجفيف مع الفرن الكهربائي على وفق

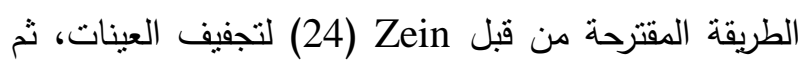




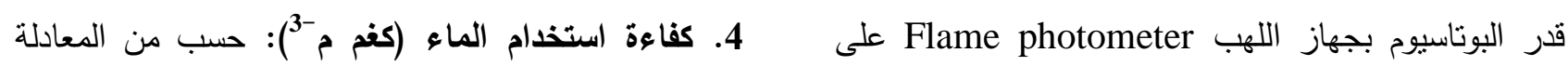

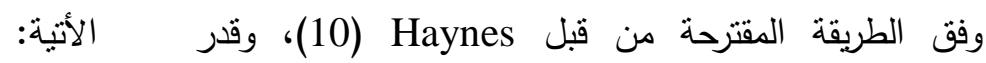

$$
\begin{aligned}
& W U E=\frac{G Y}{W A}
\end{aligned}
$$

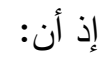

$$
\begin{aligned}
& \text { = WUE } \\
& \text { = حاصل البذور (كغم هـ = GY } \\
& \text { =WA }
\end{aligned}
$$

الفسفور باستعمال مولبيدات الامونيوم وحامض الأسكوربيك وباستخدام جهاز الطيف الضوئي كوليني وعلى طول موجي قدره 882 نانوميتر وكما جاء في وآخرون (20)، وقدر النتروجين في الجزء الخضري باستعمال

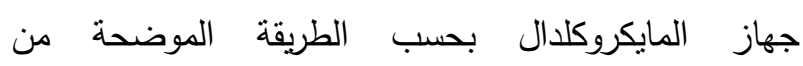
قبل Bremher (6) والمبينة في Page وآخرون (20).

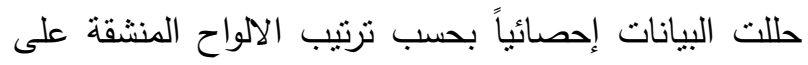
وفق تصميم RCBD وتمت مقارنة المتوسطات الحسابية للمعاملات باستخدام اقل فرق معنوي (LSD) على مستوى 2. محتوى الأولق من الكلوروفيل (ملغم غم -1' وزن رطب): قدر على وفق طريقة Linchtenthaler التي ذكرها

.(25) Kirkham, 3. نسبة الزيت في البذور (2\%): قدرت على اساس الوزن الجاف للبذور باستعمال بجهاز (Sexhlet).

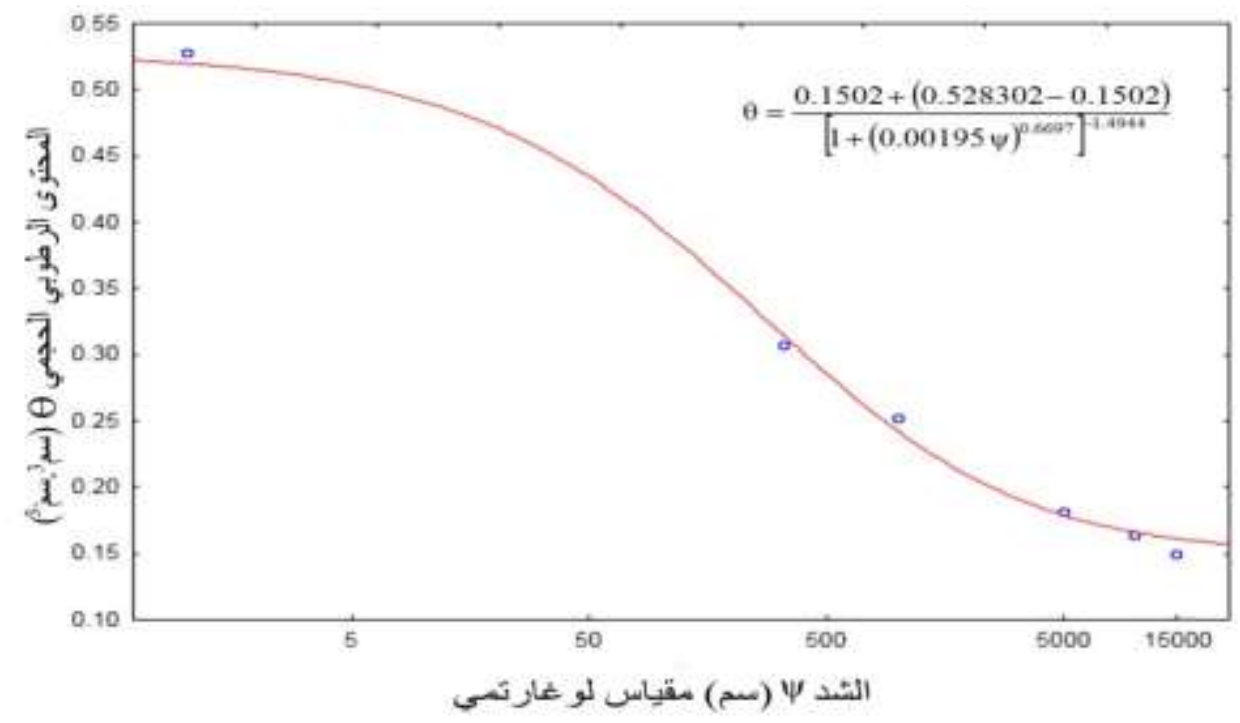

شكل 1. منحنى الوصف الرطويي للتربة المستخدمة في الدراسة

\begin{tabular}{|c|c|c|c|c|c|}
\hline \multicolumn{6}{|c|}{ الموسم الربيعي 2012} \\
\hline الاستهلاك موسم-1-1ائي & كمية الامطار & مل ملق المضاء & كمية المستعل & الريات & طرائق الري \\
\hline 425 & \multirow{4}{*}{5} & 420 & 4167 & 12 & ري المروز (I) \\
\hline 255 & & 250 & 2539 & 12 & ري تبادلي متغير (I2) \\
\hline 255 & & 250 & 2539 & 12 & ري تبادلي ثابت (I3) \\
\hline 425 & & 420 & 4167 & 12 & ري الألواح (I) \\
\hline \multicolumn{6}{|c|}{ الموسم الربيعي 2013} \\
\hline 364 & \multirow{4}{*}{23.8} & 340 & 3389 & 12 & ري المروز (I) \\
\hline 234 & & 210 & 2065 & 12 & ري تبادلي متغير (I2) \\
\hline 234 & & 210 & 2065 & 12 & ري تبادلي ثابت (I3) \\
\hline 364 & & 340 & 3389 & 12 & ري الألَّاح (I) \\
\hline
\end{tabular}

جدول 1. كمية الماء المستعمل وعدد الريات والاستهلاك المائي لمحصول زهزة الثمس لطرائق الري للموسمين الربيعيين 2012 و2013 
يوضح جدول 2 وجود تداخل معنوي بين عاملي الدراسة في نسبة النايتروجين في الأوراق، ففي الموسم الأول اعطت معاملة الري I3 والثدة 3000 كاوس أعلى نسبة نايتروجين في الأوراق بلغت 3.937\% ولم تختلف معنويا عن استعمال

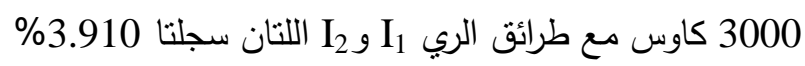

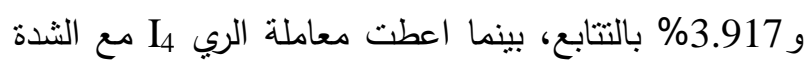
1000 أقل نسبة نايتروجين في الأوراق بلغت بكابع، 2.540\%. وفي الموسم الثاني اعطت معاملة الري I2 مع الثدة 2000

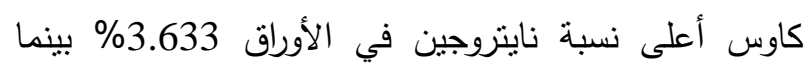
اعطت معاملة الري I4 مع الثدة 1000 أقل نسبة نايتروجين

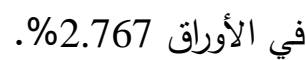
تركيز الفسفور في الأولق نوضح النتائج جدول 3 عدم وجود نأثير معنوي لطرائق الري الرئ في تركيز للفسفور في الأوراق في الموسم الأول، أما في الموسم الثاني فقد تفوقت طريقة الري I2 معنويا بأعلى تركيز للفسفور في الأوراق ppm 0.3050 في حين اعطت معاملة الري I4 أقل تركيز للفسفور في الأوراق يعود السبب في ذلك إلى أن امتصاص العناصر والمغذيات التوري يكون أفضل في حالة الري التبادلي وذلك لعدم تعرض هذه الته

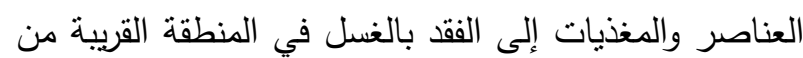
الجذور وبشكل يتتاسب مع طريقة الري وكمية المياه المعطاة، بينما كان أقل في الري التبادلي الثابت وقد يعود إلى أن

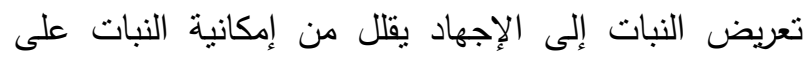

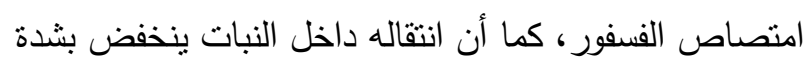
(16). يوضح جدول 3 وجود تأثير معنوي لمعاملات مغنطة مياه الري في تركيز الفسفور في الأوراق، فقد حققت الثدة 3000 كاوس أعلى تركيز للفسفور في الاوراق 0.3725

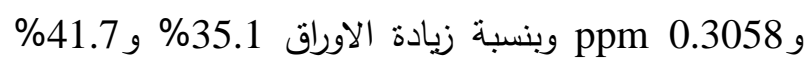
عن معاملة القياس (من دون مغنطة) التي حققت أدنى تركيز

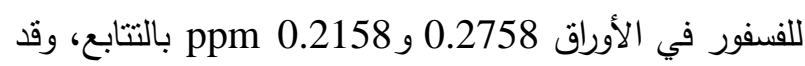
يعود السبب في زيادة تركيز الفسفور في الأوراق إلى دور

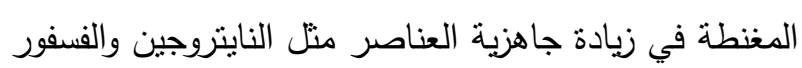
والبوتاسيوم وامتصاصها. اشار الجدول نفسه إلى وجود تداخل زيل فئل معنوي بين عاملي الدراسة في تركيز الفسفور في الأوراق

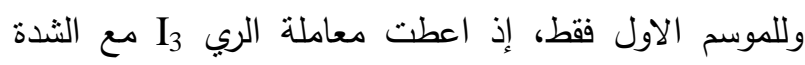
3000 كاوس أعلى تركيز للفسفور في الأوراق 0.4067
التتائج والمناقشة نسبة النايتروجين في الأوراق تنين نتائج جدول 2 وجود تأثير معنوي لطرائق الري في نسبة

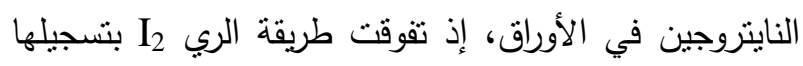
أعلى نسبة نايتروجين في الأوراق 3.639 و 3.458. I تختلف معنويا عن طريقة الري I3 بينما سجلت المعاملة أقل نسبة للنايتروجين في الأوراق 2.832 و 2.900\% للموسمين بالتتابع. ربما يرجع ذلك إلى أن قلة كمية المياه قد ادت إلى زيادة تركيز النايتروجين في الأجزاء النباتية ومنها لئه الأوراق (23). اثرت معاملات مغنطة مياه الري معنويا في نسبة النايتروجين في الأوراق، ففي الموسم الأول حققت الثندة

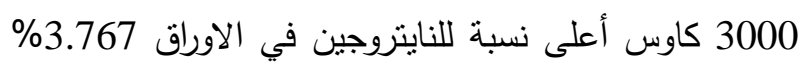
ولم تختلف معنويا عن المعاملة 2000 كاوس وبنسبة زيادة بلغت 19.6\% عن معاملة القياس (من دون مغنطة) التي حققت أدنى نسبة للنايتروجين في الأوراق تختلف معنويا عن الثدة 1000 كاوس، وفي الموسم الثاني حققت الثدة 2000 كاوس أعلى نسبة نايتروجين في الأوراق 3.375 ولم تختلف معنويا عن الثدة 3000 كاوس وبنسبة زيادة بلغت 4.8\% عن معاملة القياس التي حققت أدنى نسبة

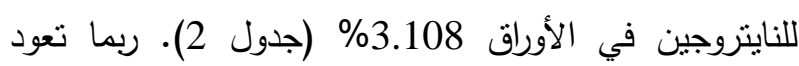
الزيادة في النايتروجين إلى دور المغنطة في زيادة جاهزية النايتروجين والفسفور والبوتاسيوم وامتصاصها.

جدول 2. تأثير طرائق الري ومغنطة مياه الري في نسبة النايتروجين في الأورلق (\%) للموسمين الربيعيين 2012 و2013

\begin{tabular}{|c|c|c|c|c|c|}
\hline \multicolumn{6}{|c|}{ الموسم الربيعي 2012} \\
\hline \multirow{2}{*}{ المتوسط } & \multicolumn{4}{|c|}{ مغنظة مياه الري (كاوس) } & \multirow{2}{*}{ طرائق الزي } \\
\hline & 3000 & 2000 & 1000 & $\mathbf{0}$ & \\
\hline 3.472 & 3.910 & 3. 580 & 3.157 & 3.243 & $\mathbf{I}_{\mathbf{1}}$ \\
\hline 3.639 & 3.917 & 3.763 & 3.623 & 3.253 & $\mathbf{I}_{2}$ \\
\hline 3.611 & 3.937 & 3.840 & 3.410 & 3.257 & $\mathbf{I}_{\mathbf{3}}$ \\
\hline 2.832 & 3.307 & 2.637 & 2.540 & 2.847 & $\mathbf{I}_{4}$ \\
\hline \multirow{3}{*}{0.122} & \multicolumn{4}{|c|}{0.207} & \multirow{3}{*}{ أ.فأف.م 0.0505} \\
\hline & 3.767 & 3.455 & 3.182 & 3.150 & \\
\hline & \multicolumn{4}{|c|}{0.105} & \\
\hline \multicolumn{6}{|c|}{ الموسم الربيعي 2013} \\
\hline \multirow{2}{*}{ المتوسط } & \multicolumn{4}{|c|}{ مغنطة مياه الري (كاوس) } & \multirow{2}{*}{ طرائق الري } \\
\hline & 3000 & 2000 & 1000 & $\mathbf{0}$ & \\
\hline 3.292 & 3.500 & 3.467 & 3.200 & 3.000 & $\overline{\mathbf{I}_{1}}$ \\
\hline 3.458 & 3.367 & 3.633 & 3.467 & 3.367 & $\mathbf{I}_{2}$ \\
\hline 3.392 & 3.333 & 3.500 & 3.467 & 3.267 & $\mathbf{I}_{3}$ \\
\hline 2.900 & 3.133 & 2.900 & 2.767 & 2.800 & $\mathbf{I}_{4}$ \\
\hline \multirow[t]{3}{*}{0.241} & \multicolumn{4}{|c|}{0.294} & أ.ف.م 0.05 \\
\hline & $\mathbf{3 . 3 3 3}$ & 3.375 & 3.225 & 3.108 & المتوسط \\
\hline & \multicolumn{4}{|c|}{0.119} & أ.ف.م 0.05 \\
\hline
\end{tabular}


الثاني حققت الثدة 3000 كاوس أعلى تركيز للبوناسيوم في

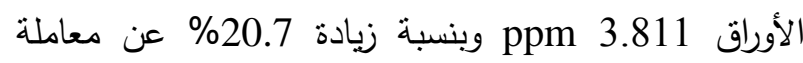
القياس التي حققت أدنى تركيز للبوتاسيوم في الأوراق 3.157

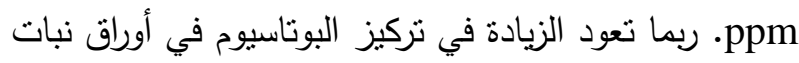

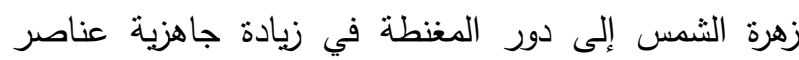

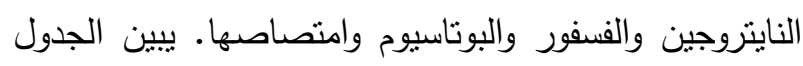
ذاته وجود تداخل معنوي بين عاملي الدراسة في تركيز

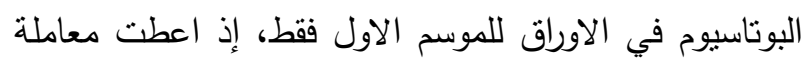
الري II مع الثدة 2000 كاوس أعلى تركيز للبوتاسيوم في الاورفي

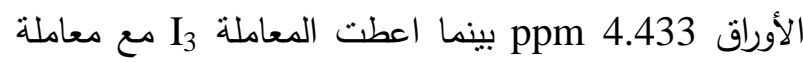

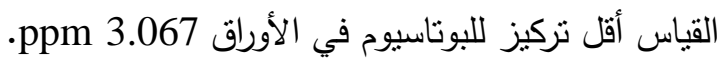
جدول 4. تأثير طرائق الري ومغنطة مياه الري في تركيز البوتاسيوم في الأورلق (ppm) للموسمين الريبعيين 2012

\section{3}

\begin{tabular}{|c|c|c|c|c|c|}
\hline \multicolumn{6}{|c|}{ الموسم الربيعي 2012} \\
\hline \multirow{2}{*}{ المتوسط } & \multicolumn{4}{|c|}{ مغتطة مياه الري (كاوس) } & \multirow{2}{*}{ طرائق الري } \\
\hline & 3000 & 2000 & 1000 & $\mathbf{0}$ & \\
\hline 4.042 & 3.700 & 4.433 & 3.667 & 3.700 & $\mathbf{I}_{1}$ \\
\hline 3.533 & 3.100 & $\mathbf{3 . 5 3 3}$ & 3.533 & 3.100 & $\mathbf{I}_{2}$ \\
\hline 3.225 & 3067 & 3.200 & 3.200 & $\mathbf{3 . 0 6 7}$ & $\mathbf{I}_{3}$ \\
\hline 3.760 & 3.633 & 3.967 & 3.967 & 3.633 & $\mathbf{I}_{4}$ \\
\hline \multirow[t]{3}{*}{0.442} & \multicolumn{4}{|c|}{$\mathbf{0 . 5 2 7}$} & أ.ف.م 0.05 \\
\hline & 3.740 & 3.717 & 3.592 & 3.375 & المتوسط \\
\hline & \multicolumn{4}{|c|}{0.208} & أ.ف.م 0.05 \\
\hline \multicolumn{6}{|c|}{ الموسم الربيعي 2013} \\
\hline \multirow{2}{*}{ المتوسط } & \multicolumn{4}{|c|}{ مغتطة مياه الري (كاوس) } & \\
\hline & 3000 & 2000 & 1000 & $\mathbf{0}$ & عزاتى الري \\
\hline 3.709 & 4.193 & 3.603 & 3.730 & 3.310 & $\mathbf{I}_{1}$ \\
\hline $\mathbf{3 . 5 0 7}$ & 3.810 & $\mathbf{3 . 3 2 7}$ & 3.540 & $\mathbf{3 . 3 5 3}$ & $\mathbf{I}_{2}$ \\
\hline 2.715 & 3.173 & 2.837 & 3.660 & 2.190 & $\mathbf{I}_{3}$ \\
\hline 3.760 & 4.067 & 3.713 & 3.483 & 3.777 & $\mathbf{I}_{4}$ \\
\hline \multirow[t]{3}{*}{0.232} & \multicolumn{4}{|c|}{ N.S } & أ.ف.م 0.05 \\
\hline & 3.811 & 3.370 & 3.353 & 3.157 & المتوسط \\
\hline & \multicolumn{4}{|c|}{0.309} & أ.ف.م 0.05 \\
\hline
\end{tabular}

محتوى الأورلق من الكلوروفيل

توضح نتائج جدول 5 أن لطرائق الري نأثنرا معنويا في الني محتوى أوراق زهرة الثمس من الكلوروفيل، فقد اعطت معاملة

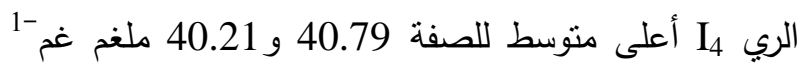

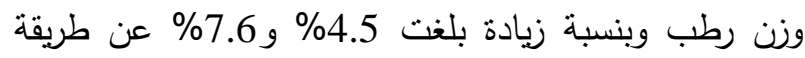

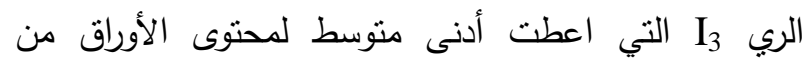

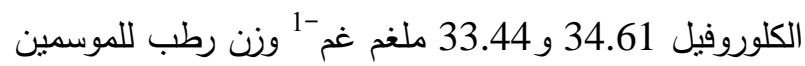
بالتتابع، وقد يعزى سبب الانخفاض إلى أن تعرض النبات

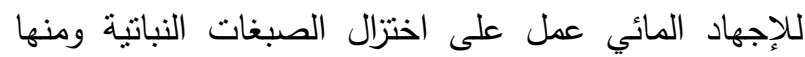

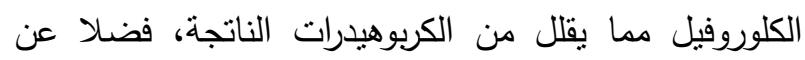
تمزق أغشية البلاستيدات الخضراء نتيجة الانكماش والهام
بينما اعطت معاملة الري I4 مع الثدة 0 (من دون

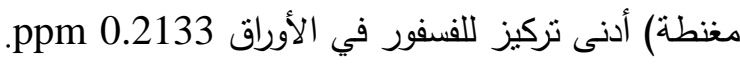
جدول 3. تأثير طرائق الري ومغنطة مياه الري في تركيز الفسفور في الأولق (ppm) للموسمين الريبعيين 2012 و2013

\begin{tabular}{|c|c|c|c|c|c|}
\hline \multicolumn{6}{|c|}{ الموسم الربيعي 2012} \\
\hline \multirow{2}{*}{ المتوسط } & \multicolumn{4}{|c|}{ مغتطة مياه الري (كاوس) } & \multirow{2}{*}{ طرائق الري } \\
\hline & 3000 & 2000 & 1000 & $\mathbf{0}$ & \\
\hline 0.3275 & 0.3433 & 0.3167 & 0.3133 & 0.3367 & $\mathbf{I}_{\mathbf{1}}$ \\
\hline 0.3508 & 0.3767 & 0.3667 & 0.3467 & 0.3133 & $\mathbf{I}_{2}$ \\
\hline 0.3342 & 0.4067 & 0.3700 & 0.3200 & 0.2400 & $\mathbf{I}_{3}$ \\
\hline 0.3008 & 0.3633 & 0.3500 & 0.2767 & 0.2133 & $\mathbf{I}_{4}$ \\
\hline \multirow[t]{3}{*}{ N.S } & \multicolumn{4}{|c|}{0.0627} & \multirow{3}{*}{ أ.ف. ألفتوسط 0.05} \\
\hline & 0.3725 & 0.3508 & 0.3142 & 0.2758 & \\
\hline & \multicolumn{4}{|c|}{0.0299} & \\
\hline \multicolumn{6}{|c|}{ الموسم الربيعي 2013} \\
\hline \multirow{2}{*}{ المتوسط } & \multicolumn{4}{|c|}{ مغتطة مياه الري (كاوس) } & \multirow{2}{*}{ طرائق الري } \\
\hline & 3000 & 2000 & 1000 & $\mathbf{0}$ & \\
\hline 0.2342 & 0.3067 & 0.2233 & 0.2100 & 0.1967 & $\mathbf{I}_{1}$ \\
\hline 0.3050 & 0.3100 & 0.3000 & 0.3200 & 0.2900 & $\mathbf{I}_{2}$ \\
\hline 0.2450 & 0.3367 & 0.2667 & 0.2233 & 0.1533 & $\mathbf{I}_{3}$ \\
\hline 0.2275 & 0.2700 & 0.2233 & 0.1933 & 0.2233 & $\mathbf{I}_{4}$ \\
\hline \multirow[t]{3}{*}{0.0381} & \multicolumn{4}{|c|}{ N.S } & أ.ف.م 0.05 \\
\hline & 0.3058 & 0.2533 & 0.2367 & 0.2158 & المتوسط \\
\hline & \multicolumn{4}{|c|}{0.0362} & أ.ف.م 0.05 \\
\hline
\end{tabular}

تركيز البوتاسيوم في الأورلق

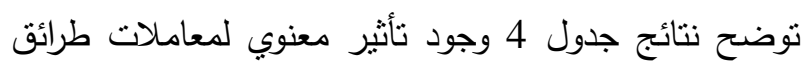
الري في تركيز البوتاسيوم في الأوراق، ففي الموسم الأول تفوقت طريقة الري II بأعلى تركيز للبوتاسيوم في الأوراق

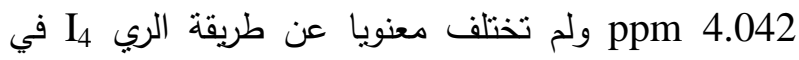
حين اعطت معاملة الري I3 أقل تركيز للبوتاسيوم في الأوراق

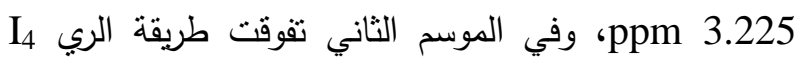

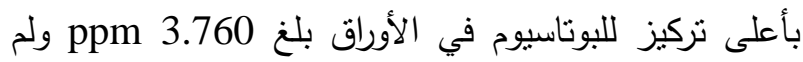

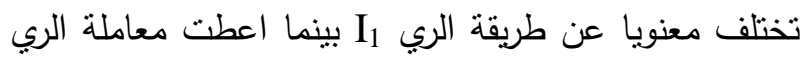

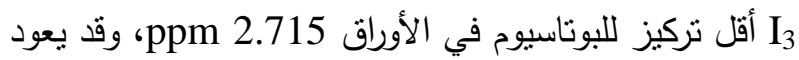
سبب انخفاض نسبة البوتاسيوم في الأوراق عند معاملات

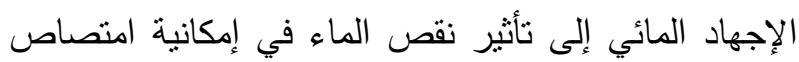

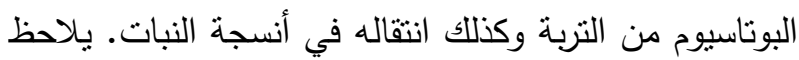
من بيانات جدول 4 وجود تأثير معنوي لمعاملات مغنطة التئل مياه الري في تركيز البوتاسيوم في الأوراق، ففي الموسي

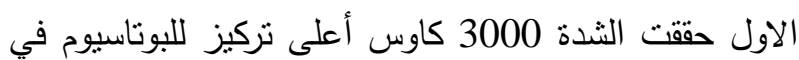
الأوراق الاول 3.740 الكنها لم تختلف معنويا عن الثدتين

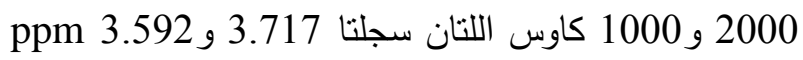
وبنسبة زيادة 10.8\% عن معاملة القياس التي حققت أدنى

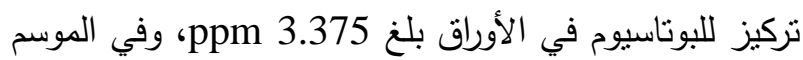


نسبة الزيت في البذور

يتضح من الجدول 6 وجود تأثير معنوي لمعاملات طرائق البدون

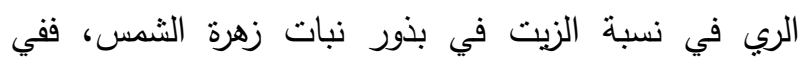

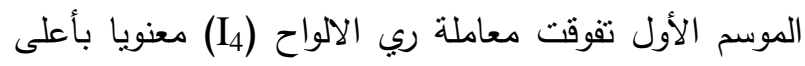

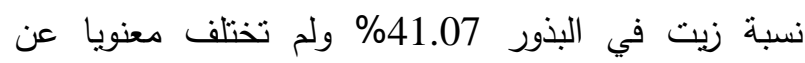

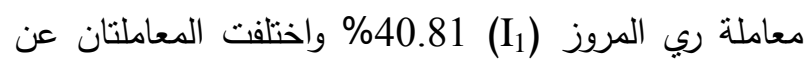
معاملتي الري التبادلي المتغير (I2) (I2) 38.40\% ومعاملة الري التبادلي الثابت (I3) التي اعطت أقل نسبة زيت بالبذور التبغر

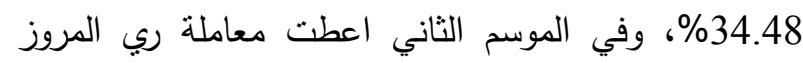
(II)

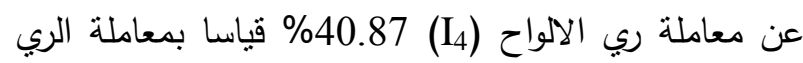
التبادلي الثابت (I/3) التي اعطت أقل نسبة زيت بالبذور 36.26 ولم تختلف معنويا عن الري التبادلي المتغير (I2) التي اعطت 67.67\%. قد يرجع سبب انخفاض نسبة الزيت

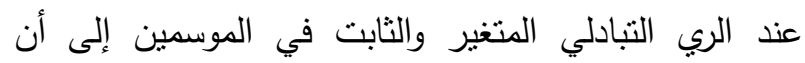
الإجهاد المائي يؤثز في عملية التمثيل الكربوني وبذلك يقل تجهيز نواتج التمثيل إلى البذور مما يسبب انخفاض الزئ الزيت التهني في البذور. تتفق هذه النتيجة مع ما توصل إليه البهون باحثين

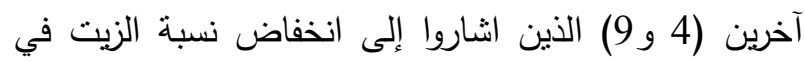

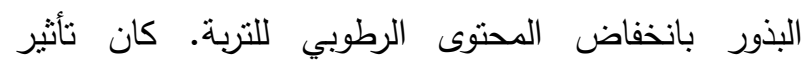
معاملات مغنطة مياه الري معنوي ولكلا الموسمين (جدول

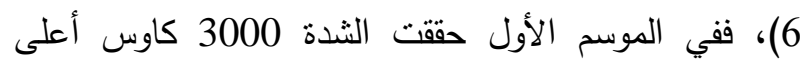
نسبة زيت في البذور بلغت 39.73\% ولم تختلف معنويا عن الن الثدة 2000 كاوس 38.99\% وبنسبة زيادة بلغت 5.0\% عن معاملة القياس التي حققت أدنى نسبة للزيت 37.83\%

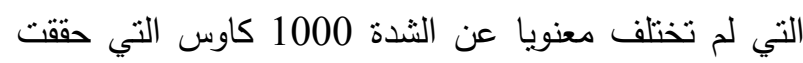
38.21\%، وفي الموسم الثاني حققت الثدة 3000 كاوس أعلى نسبة الزيت 39.72\% ولم تختلف معنويا عن الثدنين 1000 و 2000 كاوس اللتان حققتا 38.74 و 39.69 \% بالتتابع وبنسبة زيادة بلغت 5.6\% عن معاوس معاملة القياس التي

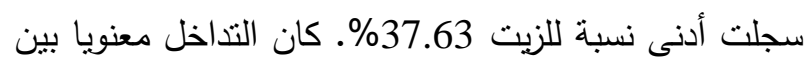
عاملي الدراسة في نسبة الزيت في البذور (جدول 6)، فقد

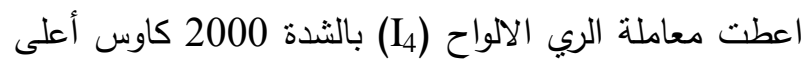

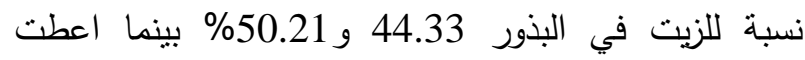
معاملة الري التبادلي الثابت بالثدة 2000 كاوس ومعاملة
الأنزيمي للأغشية (23). تتفق هذه النتيجة مع ما ذكره Hassan

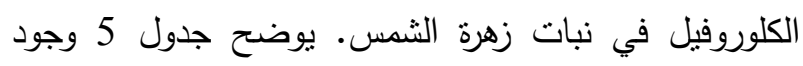
تأثثر معنوي لمعاملات مغنطة مياه الري في محتوى الأوراق

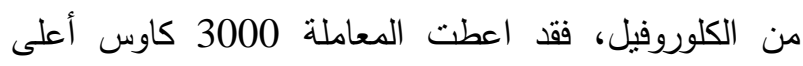
متوسط للصفة 43.03 و42.39 ملغم غم -1 وزن رطب بزيادة بلغت 28.0 و35.2\% عن معاملة القياس الني اعطت أدنى

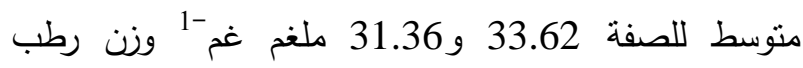
للموسمين بالتتابع. ربما يعود السبب إلى دور المغنطة في ولى ولي زيادة صبغات التشثيل الضوئي بسبب زيادة السايتوكاينين الذي يؤدي دورا مهما في تطور البلاستيدات الخضراء واستحثاث عدد من الجينات المسؤولة عن نطور البلاستيدات الخضراء (5). كما اشار الجدول ذاته إلى وجود تداخل معنوي بين عاملي الدراسة في محتوى الأوراق من الكلوروفيل

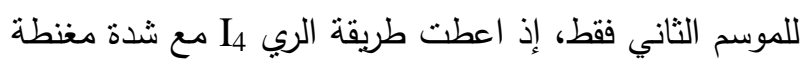
3000 كاوس أعلى منوسط لمحتوى الأوراق من الكلوروفيل

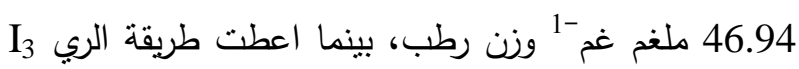
مع شدة المغنطة 0 كاوس (القياس) أقل متوسط لمحتوى الأوراق من الكلوروفيل 29.04 ملغم غم -1 وزن رطب. جدول 5. تأثير طرائق الري ومغنطة مياه الري في محتوى

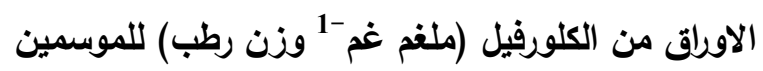

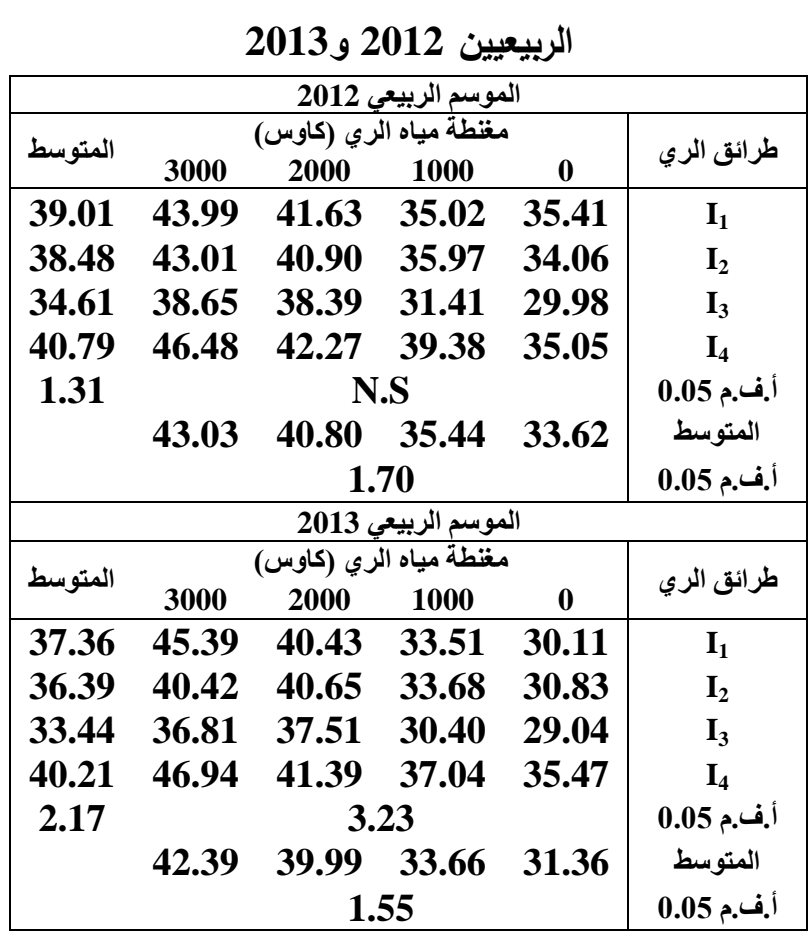


استعمال المياه في الري التبادلي وحصلنا على حاصل بدون

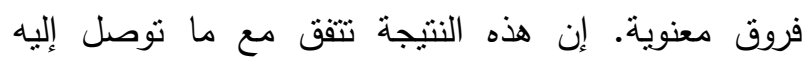
Nihaba لنبات زهرة الثمس في كفاءة استعمال الماء. جدول 7. تأثير طرائق الري ومغنطة مياه الري في كفاءة استعمال الماء (كفم م-3

2013

\begin{tabular}{|c|c|c|c|c|c|}
\hline \multicolumn{6}{|c|}{ الموسم الربيعي 2012} \\
\hline \multirow{2}{*}{ المتوسط } & \multicolumn{4}{|c|}{ مغظطة مياه الري (كاوس) } & \multirow{2}{*}{ طرائق الري } \\
\hline & 3000 & 2000 & 1000 & $\mathbf{0}$ & \\
\hline 0.74 & 0.86 & 0.84 & 0.67 & 0.60 & $\mathbf{I}_{\mathbf{1}}$ \\
\hline 1.21 & 1.42 & 1.33 & 1.09 & 0.99 & $\mathbf{I}_{2}$ \\
\hline 1.11 & 1.40 & 1.09 & 1.03 & 0.93 & $\mathbf{I}_{3}$ \\
\hline 0.73 & 0.86 & 0.83 & 0.65 & 0.60 & $\mathbf{I}_{4}$ \\
\hline \multirow[t]{2}{*}{0.05} & \multicolumn{4}{|c|}{ N.S } & أ.ف.م 0.05 \\
\hline & 1.13 & 1.02 & $\begin{array}{l}0.86 \\
6\end{array}$ & 0.78 & أ.ف.م. \\
\hline \multicolumn{6}{|c|}{ الموسم الربيعي 2013} \\
\hline \multirow[t]{2}{*}{ المتوسط } & \multicolumn{4}{|c|}{ مغنطة مياه الري (كاوس) } & ط ائة اللّ \\
\hline & 3000 & 2000 & 1000 & $\mathbf{0}$ & صنائ اتري \\
\hline 0.83 & 0.97 & 0.94 & 0.76 & 0.67 & $\mathbf{I}_{\mathbf{1}}$ \\
\hline 1.34 & 1.57 & 1.45 & 1.24 & 1.10 & $\mathbf{I}_{2}$ \\
\hline 1.23 & 1.53 & 1.43 & 1.18 & 0.78 & $\mathbf{I}_{3}$ \\
\hline 0.83 & 0.96 & 0.92 & 0.75 & 0.67 & $\mathbf{I}_{4}$ \\
\hline \multirow[t]{3}{*}{0.12} & \multicolumn{4}{|c|}{ N.S } & أ.ف.م 0.05 \\
\hline & 1.26 & 1.18 & 0.98 & 0.81 & المتوسط \\
\hline & \multicolumn{4}{|c|}{0.16} & أ.ف.م 0.05 \\
\hline
\end{tabular}

تبين النتائج في جدول 7 وجود تأثثر معنوي لمعاملات مغنطة مياه الري في منوسط كفاءة استعمال الماء، فقد حققت الثدة 3000 كاوس أعلى متوسط لكفاءة استعمال الماء 1.13 و1.26 كغم م -3 ولم تختلف معنويا عن معاملة مغنطة

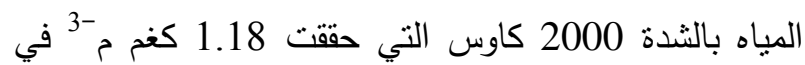
الموسم الثاني فقط، واختلفت معنويا عنها في الموسم الأول

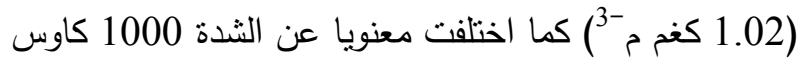

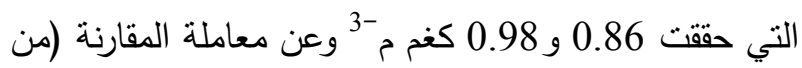
دون مغنطة) التي حققت أقل منوسط لكفاءة استعمال الماء 0.78 و 0.81 كغم م-3 للموسمين بالتتابع. قد يعود سبب لـفي ذلك إلى دور المغنطة في زيادة جاهزية العناصر وامتصاصها وتفكيك جزيئات الأملاح في التربة وتحسين خواص المياه الفيزيائية والكيمياوية وتحسين صفات النمو الخضري والجذري ودورها في زيادة الوزن الجاف الكلي

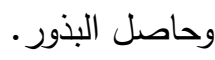

الري التبادلي الثابت من دون مغنطة أقل نسبة للزيت في البذور 31.23\% و 35.55\% للموسمين بالتتابع. جدول 6. تأثير طرائق الري ومغنطة مياه الري في نسبة

الزيت (\%) للموسمين الريبعيين 2012 و2013

\begin{tabular}{|c|c|c|c|c|c|}
\hline \multicolumn{6}{|c|}{ الموسم الربيعي 2012} \\
\hline المتوسط & \multicolumn{4}{|c|}{ مغتطة مياه الري (كاوس) } & طرائق الري \\
\hline 40.81 & 41.80 & 41.80 & 40.74 & 38.91 & $\mathbf{I}_{1}$ \\
\hline 38.40 & 39.51 & 38.59 & 37.57 & 37.95 & $\mathbf{I}_{2}$ \\
\hline 34.48 & 36.24 & 31.23 & 34.69 & 35.75 & $\mathbf{I}_{3}$ \\
\hline 41.07 & 41.38 & 44.33 & 39.85 & 38.73 & $\mathbf{I}_{4}$ \\
\hline \multirow[t]{3}{*}{1.00} & \multicolumn{4}{|c|}{2.38} & أ.ف.م 0.05 \\
\hline & 39.73 & 38.99 & 38.21 & $\mathbf{3 7 . 8 3}$ & المتوسط \\
\hline & \multicolumn{4}{|c|}{1.30} & أ.ف.م 0.05 \\
\hline \multicolumn{6}{|c|}{ الموسم الربيعي 2013} \\
\hline المتوسط & \multicolumn{4}{|c|}{ مغتطة مياه الري (كاوس) } & قالري \\
\hline & 3000 & 2000 & 1000 & 0 & \\
\hline 41.00 & 42.55 & 42.61 & 40.68 & 38.15 & L \\
\hline 37.67 & 36.36 & 39.61 & 36.54 & 38.16 & $\mathbf{I}_{2}$ \\
\hline 36.26 & 35.53 & 36.34 & 37.61 & 35.55 & $\mathbf{I}_{\mathbf{3}}$ \\
\hline 40.87 & 44.45 & 50.21 & 40.13 & 38.68 & $\mathbf{I}_{4}$ \\
\hline \multirow[t]{3}{*}{1.43} & \multicolumn{4}{|c|}{2.11} & أ.ف.م 0.05 \\
\hline & 39.72 & 39.69 & 38.74 & 37.63 & المتوسط \\
\hline & \multicolumn{4}{|c|}{1.01} & أ.ف.م 0.05 \\
\hline
\end{tabular}

كفاءة استعمال الماء

يوضح جدول 7 وجود تأثنير معنوي لمعاملات الري في كفاءة

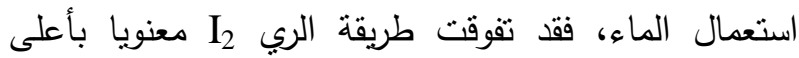

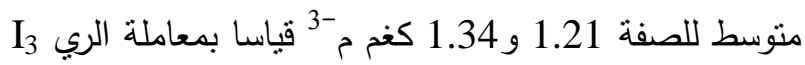

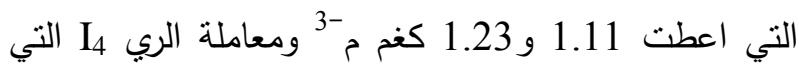
اعطت أقل متوسط لكفاءة استعمال الماء 0.73 و 0.83 كغم م" التي لم تختلف معنويا عن المعاملة I التي اعطت 0.74 و 0.83 كغم م -3 للموسمين بالتتابع. قد يعزى انخفاض كفاءة استعمال الماء الحقلي عند معاملة ري المروز ومعاملة ري الألواح إلى زيادة كمية مياه الري بالنسبة إلى كمية

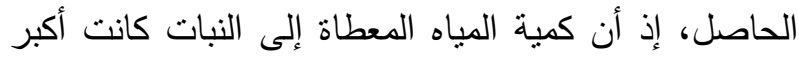

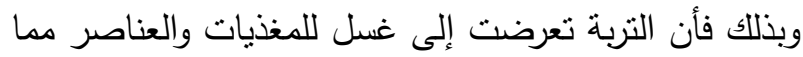
انعكس بشكل سلبي في الحاصل وقلة كفاءة استعمال الماء (15). أما بالنسبة إلى ري المروز التبادلي الثابت والمتغير فقد ادى استخدام 60\% من الماء بالنسبة إلى الحاصل إلى بلى زيادة الكفاءة كون استعمال كميات مياه اقل في الري التبادلي المتغير والثابت قد زاد من امتصاص العناصر والمغذيات من لند قبل النبات من التربة وعدم تعرض التربة للغسل في المنطقة القريبة من الجذور ومن ثم زيادة الحاصل مقارنة بكمية المياه المضافة وبهذا فقد تم توفير 40\% من المياه وازدادت كفاءة 


\section{REFERENCES}

1. Abdul-Amer, O. Q. 2013. Growth and Yield of Sunflower (Helianthus annuus L.) at effect of Water Stress and Potassium Fertilization. M.Sc. Thesis, Dept. of Field Crop, Coll. of Agric., Univ. of Baghdad. pp. 125.

2. Agele, S. O.; I. O. Maraiyesa and I. A. Adenji. 2007. Effect of variety and row spacing on radiation interception, partitioning of dry matter and seed set efficiency in late season sunflower (Helianthus annuus L.) in a humid zone of Nigeria. Afr. J. Agric. Res. 2(3): 80-88.

3. Al-Rawi, W. M. 2001. Guidance in the Sunflower Cultivation. Public Authority for Agricultural Guidance and Cooperation, Ministry of Agriculture. p. 8.

4. Ardiarini, N.; R. Kusriningrum and A. Kuswanto. 2013. The path analysis on yield due to the sunflower (Helianthus annuus L.) oil under drought stress. J. Basic. Appl. Sci. Res. 3(4): 1-7.

5. Atak, C.; O. Emiroglu; S. Aklimanoglu and A. Rzakoulieva. 2003. Stimulation of regeneration by magnetic field in soybean (Glycine max L. Merrill) tissue cultures. J Cell Mol. Biol. 2: 113-119.

6. Bremher, J. M. 1965. Nitrogen availability index. in C. A. Black, (edr.). Methods of Soil Analysis. Am. Soc. Agron. Inc. Agron. Mono. 9. Medison, Wisconsin, USA. p. 1324-1325.

7. Cresser, M. E. and G. W. Porsons. 1979. Sulphuric, perchloric and digestion of plant material for determination nitrogen, phosphorus, potassium, calcium and magnesium. Analytical Chemical. Acta. 109. 431-436.

8. Elsahookie, M. M., F. Oraha and A. Humood. 2006. Role of alternative irrigation, father lines for mothers and site in the sunflower performance. Iraqi J. Agric. Sci. 37 (1): 117-122.

9. Hassan, A. A. 2014. Role of Absicic Acid in Sunflower Tolerant of Drought. M.Sc. Thesis, Coll. of Agric., Univ. of Baghdad. pp. 115.

10. Haynes, R. J. 1980. A comparison of two modified Kjedhal digestion techniques for multi elements plant analysis with conventional wet and dry ashing methods. Soil Sci., and Plant Analysis. 11(5): 459-467.
11. Hillel, D. 1980. Application of Soil Physics. Academic press. Inc. New York. p. 116-126.

12. Iqbal, N.; M. Y. Ashraf and F. Azam. 2005. Effect of exogenous application of glycinebetaine on capitulum size and achene number of sunflower under water stress. International J. Biol. Biot. 2(3): 765-771.

13. Kohnke, H. 1968. Soil Physics. Mc Graw Hill Book Company, Inc. New York, USA. p. 105-108.

14. Kronenberg, K. 2005. Magneto Hydrodynamics: The Effect of Magnets on Fluids GMX International. corporate@ gmxinterhatinal.com.

15. Lehrsch, G. A.; R. E. Sojka and D. T. Westermann. 2001. Furrow irrigation and $N$ management strategies to protect water quality. Commun. Soil Sci. Plant Anal. 32(7): 1029-1050.

16. Leibersbach, H.; S. Tengrobe and B. Claassen. 2004. Roots regulation transport to counteract reduce mobility in dry soil. Plant \& Soil Sci. 95: 221-231.

17. Masoud, T. K. 2013. Role of Partial Irrigation of Rows and Organic Matter in the Water Requirement, Growth and Yield of sunflower. M.Sc. Thesis, Dept. of Soil Sci., and Water Resources, Coll. of Agric., Univ. of Baghdad. pp. 112.

18. Morejon, L.P.; J. C. C .Palacio; L. V. Abad; A. P. Abadand and L. V. Govea. 2007. Stimulation of Pinus tropicalis seeds by magnetically treated water. Int Agrophysics. 21:173-177.

19. Nihaba, R. S. 2011. Rows alternative irrigation of sunflower in the province of Babylon area. Euphrates J. Agric. Sci. 3(1): 43-48.

20. Page, A. I. 1982. Methods of Soil Analysis. Part 2. Chemical and Microbiological Properties. Amer. Soc. Agron. Midison. Wisconsin. USA. pp. 400.

21. Putt, E. D. 1997. History and present world stated. in A. A. Schneiter (edr.). Sunflower Technology and Production. Agron. Monoger 35, ASA, CSSA and SSSA, Madison, Wl. p. 21-25

22. Steel, G. D. and J. H. Torrie. 1980. Principles and Procedures of Statistics. Mc Graw. Hill Book Company, Inc. New York, USA. pp. 480. 
23. Wang, Z.; F. Liu; S. Kang and C. R. Jenson. 2012. Alternate partial root-zone drying irrigation improves nitrogen nutrition in maize (Zea mays L.) leaves. Environ., Expl. Bot. 75: 36-40.

24. Zein, A. K. 2002. Rapid determination of soil moisture content by the microwave oven drying method. Sudan Engineering Soc. J. 48(40): 43-54.

25. Zhang, J. and M. B. kirkham. 1996. Antioxidant responses to drought in sunflower and sorghum seedling. New Phytol. 132: 361373. 